\title{
Síndrome de Ramsay Hunt: uma revisão sistemática
}

\author{
Ramsay Hunt syndrome: a systematic review
}

Síndrome de Ramsay Hunt: una revisión sistemática

Ursula Tatiane de Farias Hounsell Almeida ${ }^{1 *}$, Rafael de Azevedo Silva ${ }^{1}$, Antonio Hounsell Almeida ${ }^{2}$, Leonardo Mendes Acatauassu Nunes ${ }^{3}$.

\section{RESUMO}

Objetivo: Realizar revisão sistemática sobre a Síndrome de Ramsay Hunt, abordando seus aspectos etiológicos, os fatores de risco, as manifestações clínicas, o diagnóstico e o tratamento. Métodos: A pesquisa foi realizada a partir das bases de dados: SciELO, Medline, LILACS por meio dos descritores: Paralisia facial AND Herpes Zoster de Orelha Externa AND Síndrome Ramsay Hunt. No Pubmed, foram utilizados termos do MESH, Facial Paralisy AND Herpes Zoster Oticus. Foram incluídos artigos publicados entre 2017 e 2019 sobre o assunto e dois livros de otorrinolaringologia. Resultados: A busca produziu um total de 291 artigos, foram retirados 265 por não estarem no critério de tempo e 10 por estarem duplicados em bases de dados. Destes, 16 artigos atenderam aos critérios de inclusão previamente estabelecidos. A busca por livros em otorrinolaringologia resultou na inclusão de 2 livros que abordaram a temática de forma ampla e detalhada. Considerações Finais: Foi possível constatar a heterogeneidade nos estudos sobre a síndrome. Entretanto, todos apontam para a importância de seu reconhecimento, característica clínica e seguimento; uma vez que o rápido diagnóstico e tratamento diminuem o tempo de doença ativa, reduz o dano neural e possível neuralgia pós-herpética.

Palavras-chave: Paralisia facial, Herpes zoster da orelha externa, Herpesviridae.

\begin{abstract}
Objective: To conduct a systematic review of Ramsay Hunt Syndrome, taking into account the etiological aspects, risk factors, clinical manifestations, diagnosis and treatment. Method: The research was carried out from the following databases: SciELO, Medline, LILACS using descriptors: Facial Paralysis AND External Ear Herpes Zoster AND Ramsay Hunt Syndrome. For Pubmed search, MESH, Facial Paralisy AND Herpes Zoster Oticus were used. We included articles published between 2017 and 2019 on the subject and two books of otorhinolaryngology. Results: The search produced a total of 291 articles, 265 were removed for not being in the time criterion and 10 for being duplicated in databases. Of these, 16 articles met previously established inclusion criteria. The search for books on otorhinolaryngology resulted in the inclusion of 2 books that approached the theme in a broad and detailed way. Final Considerations: It was possible to verify the heterogeneity in the studies on the syndrome. However, everyone points to the importance of their recognition, clinical characteristics and follow-up; since rapid diagnosis and treatment shorten the duration of active disease, reduces neural damage and possible postherpetic neuralgia.
\end{abstract}

Key words: Facial paralisy, Herpes zoster oticus, Herpesviridae.

${ }^{1}$ Centro Universitário Metropolitano da Amazônia (UNIFAMAZ), Belém - PA. *E-mail: ursula.tati@ymail.com

${ }^{2}$ Médico Otorrinolaringologista, Tucuruí - PA.

${ }^{3}$ Centro Universitário do Estado do Pará (CESUPA), Belém - PA.

SUBMETIDO EM: 5/2020

ACEITO EM: 6/2020

PUBLICADO EM: 8/2020

REAS/EJCH | Vol.Sup.n.55 | e3899 | DOI: https://doi.org/10.25248/reas.e3899.2020 Página 1 de 11 


\section{RESUMEN}

Objetivo: Realizar revisión sistemática sobre el síndrome de Ramsay Hunt, sus aspectos etiológicos, factores de riesgo, manifestaciones clínicas, diagnóstico y tratamiento. Métodos: La investigación se realizó en las bases de datos: SciELO, Medline, LILACS a través de los descriptores: Parálisis Facial y Herpes Zoster del Oído Externo y Síndrome de Ramsay Hunt. En Pubmed, se utilizaron los términos MESH, Paralisy Facial y Herpes Zoster Oticus. Se incluyeron publicaciones entre 2017 y 2019 sobre el tema y dos libros sobre otorrinolaringología. Resultados: La búsqueda de la investigación produjo un total de 291 artículos, 265 fueron eliminados por no cumplir con el criterio de tiempo y 10 por duplicarse en las bases de datos. De estos, 16 artículos cumplieron con los criterios de inclusión previamente establecidos. La búsqueda de libros sobre otorrinolaringología resultó en la inclusión de 2 libros que abordaron el tema de manera amplia y detallada. Consideraciones Finales: Fue posible verificar la heterogeneidad en los estudios sobre el síndrome. Sin embargo, todos señalan la importancia de su reconocimiento, características clínicas y seguimiento; Dado que el diagnóstico y el tratamiento rápidos disminuyen el tiempo de enfermedad activa, reduce el daño neural y la posible neuralgia posherpética.

Palabras clave: Parálisis facial, Oído externo herpes zoster, Herpesviridae.

\section{INTRODUÇÃO}

A paralisia facial periférica (PFP) corresponde à paralisia flácida da musculatura da mímica facial de toda a hemiface, resultado da disfunção do VII nervo craniano, o nervo facial, o que pode ocorrer desde seu núcleo protuberancial até sua junção neuromuscular. Constituindo a lesão periférica mais comum dos nervos cranianos, a PFP pode ser primária - também conhecida como paralisia de Bell - ou secundária a múltiplos fatores, como traumatismo cranioencefálico, tumores e as infecções virais, causa muito frequente (PILTCHER OB, et al., 2015; VALE SO, et al., 2019; SONG H, et al., 2018).

Dentre as infecções virais causadoras de PFP, as originadas pelo vírus varicela zoster são as mais frequentes, com incidência entre $4,5 \%$ a $9 \%$ destes casos. Tal acometimento foi descrito por James Ramsey Hunt, em 1907, que a caracterizou como Síndrome de Ramsey Hunt do tipo II ou herpes Zóster ótico (CARRICO C, 2011; GALLEGO MPO, et al., 2016; VALE SO, et al., 2019; SONG H, et al., 2018; RAJATI M e ZARRINGHALAM MA, 2019; ORTEGA MMM, et al., 2017).

A manifestação clínica é frequente em $60 \%$ a $90 \%$ dos casos, pela presença de otalgia, erupção vesicular na orelha, podendo acometer o pavilhão auricular, meato acústico externo e membrana do tímpano; e, devido a anastomose entre os nervos corda do tímpano e lingual, tais erupções também podem ser observadas na mucosa oral e língua; além de dormência facial, alteração do paladar, zumbido, tontura, nistagmo e paralisia facial periférica (PILTCHER OB, et al., 2015; SONG H, et al., 2018; RAJATI M e ZARRINGHALAM MA, 2019; JEON Y e LEE H, 2018; JI Y, et al., 2019).

O diagnóstico é eminentemente clínico, podendo-se recorrer a exames complementares em situações específicas. O diagnóstico precoce é de grande importância, pois diferentemente da paralisia de Bell, a incidência é alta de sequelas motoras e sensitivas na síndrome de Ramsay Hunt e com baixas taxas de recuperação espontânea, além da repercussão estética e funcional que podem afetar a qualidade de vida do paciente acometido (PILTCHER OB, et al., 2015; SONG H, et al., 2018; ORTEGA MMM, et al., 2017; JEON Y e LEE H, 2018).

O tratamento medicamentoso é realizado com corticosteroides e antivirais e é de grande importância seu início dentro das primeiras 72 horas. Também é recomendada terapia não medicamentosa, com fisioterapia, acupuntura e massagens terapêuticas (PILTCHER OB, et al., 2015; SONG H, et al., 2018; ORTEGA MMM, et al., 2017; JEON Y e LEE H, 2018).

O presente artigo trata-se de uma revisão sistemática sobre a Síndrome de Ramsay Hunt; uma vez que, sua rara apresentação torna seu diagnóstico difícil e tardio e assim, acarretando atraso no tratamento e possíveis lesões permanentes aos indivíduos acometidos. Ademais, a escassez de estudos a respeito da 
Síndrome, sendo a grande maioria "relato de caso", instiga ao conhecimento científico atualizado sobre o tema.

\section{MÉTODOS}

O presente estudo é uma revisão sistemática da literatura sobre a Síndrome de Ramsay-Hunt desenvolvida com produções técnicas e científicas indexadas nas bases de dados eletrônicas: Scientific Electronic Library Online (SciElo), Literatura Latino-Americana e do Caribe em Ciências da Saúde (LILACS), Medical Literature Analysis and Retrieval System Online (Medline), Pubmed e com dados recolhidos de livros de Otorrinolaringologia sobre a temática.

Para o levantamento das pesquisas, foi determinada a utilização de artigos que fossem encontrados nos idiomas Português, Inglês e Espanhol por meio do sistema de busca "Paralisia Facial" com o operador booleano AND "Herpes Zoster da orelha Externa" e operador booleano OR "Síndrome de Ramsay Hunt" buscados no DECS (Descritores em Saúde) nas bases de dados SciElo, LILACS e Medline para ampliar o número de publicações encontradas.

Para a busca de artigos na base PUBMED, foram usados termos do MESH (Medical Subject Headings) com operadores booleanos desenvolvendo o sistema de busca "Facial Paralisy" AND "Herpes Zoster Oticus" para aumentar a coleta de artigos.

Foram incluídos os artigos indexados nas bases de dados acima publicados dentro do recorte temporal de 2017 a 2019. Foram excluídos os artigos que não falavam sobre a síndrome, publicados fora do período temporal analisado, os que se repetiam nas bases de dados e os que não eram disponibilizados na íntegra. A busca por livros em otorrinolaringologia resultou na inclusão de 2 livros que abordaram a temática de forma ampla e detalhada, explanando desde sua etiologia até o tratamento. Optou-se por não se realizar um estudo metanalítico em virtude da heterogeneidade dos artigos incluídos nesta revisão.

\section{RESULTADOS}

Foram encontrados 219 artigos publicados e 2 livros de otorrinolaringologia, sendo 6 da SciElo (no idioma português), 6 no LILACS, 61 no Medline (todos em inglês), 218 no Pubmed (todos em inglês). Do total descrito acima, o primeiro processamento de dados foi a exclusão de artigos publicados fora do período estabelecido. Desse modo, foram excluídos 265 artigos, restando 26 publicações para a próxima fase de análise de dados. No segundo processamento de dados, foram excluídos artigos que não estavam publicados na íntegra, não pudessem ser acessados de forma gratuita, repetidos nas bases de dados ou que não falavam da temática da síndrome de Ramsay Hunt, sendo excluídos 10 artigos, restando 16 publicações e 2 livros de otorrinolaringologia para a análise dos dados (Figura 1). 
Figura 1 - Processamento de dados para composição da revisão. Belém, 2020.

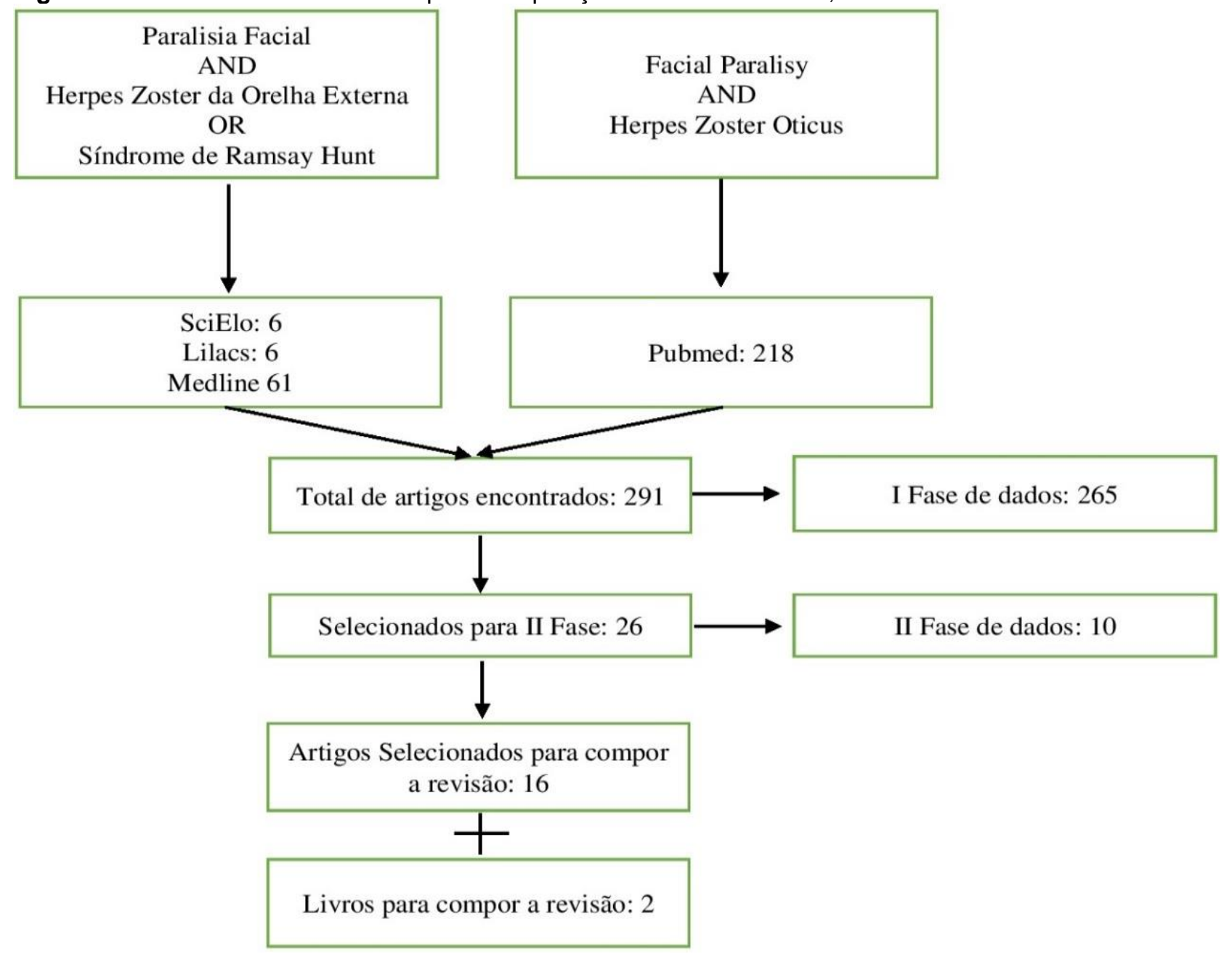

Fonte: Almeida UTFH, et al., 2020.

\section{Síntese da pesquisa}

Conforme a presente revisão, a síndrome de Ramsay Hunt é estudada desde o século XX quando fora descrita pela primeira vez (BERARDINO FD e ZANETTI D, 2018; ARYA D, et al., 2018; ZHENG RW, et al., 2017). A percepção negativa a saúde da população acometida foi observada nos dezoito estudos que compõe esta pesquisa. Quanto aos itens etiologia, fatores de risco, manifestação clínica, diagnóstico e tratamento os resultados serão apresentados como subitens no decorrer do texto para melhor avaliação.

Observamos ainda a escassez de pesquisas a respeito da síndrome, dentre as encontradas, predominância de trabalhos científicos internacionais sobre as produções nacionais. Dentre os estudos incluídos para esta revisão 5 artigos eram provenientes dos Estados Unidos da América, 2 artigos da China, Japão e Coreia; 1 artigo da Malásia, Itália, Alemanha, Irã e apenas 1 artigo do Brasil.

\section{Etiologia}

Nove estudos relataram a reativação do vírus varicela zoster como fator causal da síndrome. Cinco estudos apenas citaram o vírus varicela zoster como agente etiológico sem, entretanto, afirmar sua reativação. Três estudos não abordaram a etiologia da doença. Apenas 1 estudo citou múltiplas causas sem detalhar quais seriam (Quadro 1).

\section{Fatores de risco}

Treze estudos abordaram a respeito dos fatores de risco, dentre os quais, o envelhecimento, história pregressa de varicela, traumatismo e imunodeficiência apresentaram-se como os mais citados. Fatores como 
diabetes mellitus, tabagismo, depressão, câncer, estresse emocional e físico, uso de fármacos, transplante de órgão e infecções são considerados relevantes, mas não se mostram de forma regular entre os pacientes. O estudo conduzido por Song et al obteve o achado fator de risco para indivíduos entre 20-30 anos divergindo com os demais estudos, no qual, a idade variou entre a quinta e nona década de vida. Cinco estudos não comentaram a respeito deste subitem (Quadro 1).

\section{Manifestações Clínicas}

Paralisia facial, otalgia e vesículas herpéticas foram citadas em dezessete estudos, compondo a tríade clássica da doença. Estudo realizado por Zheng RW, et al (2017) apresentou a forma atípica da síndrome, no qual o paciente abriu o quadro com intensa vertigem e cefaleia, seguido de paralisia facial periférica e somente após o décimo dia apresentou erupções vesiculares ao redor da orelha, evidenciando o quão desafiador é o seu reconhecimento. Já os estudos conduzidos por Song H, et al. (2018), Jeon Y et al. (2018), Berardino FD, et al. (2018) e Arya D, et al. (2018), mencionaram a forma típica - com lesões herpéticas - e atípica - sem lesões herpéticas. Outros sinais e sintomas também foram relatados, entre eles, perda auditiva, tontura, vertigem, zumbido, dor miofascial, secura ocular, rouquidão e polineurite (Quadro 1).

\section{Diagnóstico}

Os dezoito estudos relataram que o diagnóstico é eminentemente clínico por meio da história clínica, exame físico otorrinolaringológico e neurológico minuciosos, porém, se faz necessário a solicitação de exames complementares para o diagnóstico diferencial de outras patologias. Paiva e colaboradores afirmam que diante de um paciente com paralisia facial a primeira hipótese lançada será acidente vascular cerebral tornando-se necessário um exame complementar para descartar tal possibilidade. Dentre os exames solicitados, a tomografia computadorizada fora solicitada em quatro estudos para descartar possível acidente vascular encefálico; ressonância magnética aparece em sete estudos para avaliar possível lesão central ou comprometimento neural; em seis estudos a reação em cadeia da polimerase foi necessária para confirmação da doença; audiometria tonal aparece em cinco estudos como aprofundamento da pesquisa, assim como a fibroscopia laríngea em três estudos. Apenas cinco estudos obtiveram o diagnóstico de forma clínica sem a necessidade de outros exames complementares (Quadro 1).

\section{Tratamento}

Os esteroides e antivirais são as drogas preconizadas para o tratamento em dezesseis trabalhos. A prednisona e metilprednisolona foram os mais utilizados, sendo o primeiro fármaco empregado em dez artigos e o segundo em três artigos, e seu tempo de uso variou entre 5 e 14 dias. Apenas o estudo conduzido por Miniti A, et al. (2000) sugeriu a dexametasona como tratamento inicial. Entre os antivirais, o aciclovir foi prescrito em oito estudos, o valaciclovir em três estudos e em cinco estudos fora sugerido aciclovir, valaciclovir ou famcyclovir, sem, entretanto, eleger um como principal. O tempo de uso variou geralmente entre 7 e 14 dias, e os estudos de Ji Y, et al. (2019) e Tecellioglu M, et al. (2017) apresentaram o maior tempo de uso: 21 dias.

A pesquisa de Kondo N, et al. (2018) sugeriu esteroides e corticoides para terapia sem citar quais seriam, o tratamento cirúrgico era objetivo da pesquisa e os autores concluíram não ser recomendado para maiores de 60 anos. Zheng RW, et al. (2017) e Paiva ALC, et al. (2017) abordaram o tratamento não medicamentoso em associação ao medicamentoso, recomendando fisioterapia, massagens e acupuntura. Dois estudos não relataram sobre o tratamento (Quadro 1). 
Quadro 1 - Autores e os achados clínicos a respeito da Síndrome Ramsay Hunt. Belém, 2020.

\begin{tabular}{|c|c|c|c|c|c|}
\hline Autores & Etiologia & Fatores de risco & Manifestação clínica & Diagnóstico & Tratamento \\
\hline $\begin{array}{l}\text { Piltcher OB, et } \\
\text { al. (2015) }\end{array}$ & $\begin{array}{l}\text { Reativação do vírus } \\
\text { varicela zoster }\end{array}$ & $\begin{array}{c}\text { Traumas cranianos; Infecções } \\
\text { otológicas; Cirurgias; Lesões } \\
\text { tumorais }\end{array}$ & $\begin{array}{c}\text { Otalgia; Lesões cutâneas } \\
\text { herpéticas; Zumbido; Perda } \\
\text { auditive; Vertigem; } \\
\text { Nistagmo }\end{array}$ & $\begin{array}{l}\text {-Clínico: História Clínica; Exame } \\
\text { físico } \\
\text {-Exame: Tomografia; RNM; } \\
\text { Sorologia para vírus e bactérias; } \\
\text { Audiometria tonal; } \\
\text { Impedanciometria; }\end{array}$ & $\begin{array}{c}\text { Prednisona, } 1 \mathrm{mg} / \mathrm{kg} / \mathrm{dia} \\
\text { por } 7 \mathrm{dias} ; \\
\text { Valaciclovir1g } 3 \mathrm{x} \text { ao dia } \\
\text { por } 14 \text { dias }\end{array}$ \\
\hline $\begin{array}{l}\text { Vale SO, et al. } \\
(2019)\end{array}$ & $\begin{array}{c}\text { Múltiplas causas - } \\
\text { não especificado }\end{array}$ & $\begin{array}{l}\text { Diabetes mellitus; Infecções } \\
\text { virais; Tumores; Traumatismo } \\
\text { cranioencefálico }\end{array}$ & Não relatado & $\begin{array}{l}\text {-Clínico: Anamnese; Escala de } \\
\text { House-Brackmann } \\
\text {-Exame: Eletromiografia }\end{array}$ & Não relatado \\
\hline $\begin{array}{l}\text { Song } \mathrm{H} \text {, et al. } \\
(2018)\end{array}$ & $\begin{array}{l}\text { Reativação do vírus } \\
\text { varicela zoster }\end{array}$ & Idade entre $20-30$ anos & $\begin{array}{c}\text { Paralisia facial; } \\
\text { Dor ao redor da orelha; } \\
\text { Dormência facial; Alteração } \\
\text { do paladar; Secura ocular; } \\
\text { Distúrbio auditivo; } \\
\text { Tontura; Náuseas; Vômitos } \\
\end{array}$ & $\begin{array}{l}\text {-Clínico: Avaliação Clínica; } \\
\text { Escala de House; Brackmann } \\
\text {-Exame: RNM; Audiometria; } \\
\text { Eletroneuromiografia }\end{array}$ & $\begin{array}{c}\text { Metilprednisolona } 48 \mathrm{mg} \\
\text { por } 4 \text { dias. Seguido de } \\
8 \mathrm{mg} \text { a cada } 2 \text { dias; } \\
\text { Valaciclovir } 3000 \mathrm{mg} / \mathrm{dia} \\
\text { por } 7 \text { dias }\end{array}$ \\
\hline $\begin{array}{l}\text { Rajati M, et al. } \\
(2019)\end{array}$ & $\begin{array}{l}\text { Vírus varicela } \\
\text { zoster }\end{array}$ & $\begin{array}{c}\text { Envelhecimento; } \\
\text { Imunodeficiência; Estresse } \\
\text { emocional; Tabagismo; } \\
\text { Diabetes; Depressão; Câncer } \\
\text { Transplante de órgãos; } \\
\text { Imunossupressores; } \\
\text { Radio/Quimioterapia }\end{array}$ & $\begin{array}{c}\text { Paralisia facial; Otalgia; } \\
\text { Erupções vesiculares; } \\
\text { Distúrbio do movimento } \\
\text { ocular; Hipoestesia facial; } \\
\text { Dor myofascial; Sintomas } \\
\text { vestibulares; Perda } \\
\text { auditive; Paralisia das } \\
\text { pregas vocais; Neuropatias }\end{array}$ & $\begin{array}{l}\text {-Clínico: Anamnese; Exame físico } \\
\text {-Exame: Laringoscopia; } \\
\text { Audiometria }\end{array}$ & $\begin{array}{c}\text { Aciclovir; Prednisona } \\
1 \mathrm{mg} / \mathrm{kg}\end{array}$ \\
\hline $\begin{array}{l}\text { Ortega MMM, } \\
\text { et al. (2017) }\end{array}$ & $\begin{array}{l}\text { Reativação do vírus } \\
\text { varicela zoster }\end{array}$ & $\begin{array}{c}\text { Idade avançada; Baixa } \\
\text { imunidade; História primaria } \\
\text { de varicela; } \\
\text { Radio/Quimioterapia; Estresse } \\
\text { físico ou emocional; Uso de } \\
\text { fármacos }\end{array}$ & $\begin{array}{l}\text { Paralisia facial; Lesões } \\
\text { cutâneas; Hipoacusia; } \\
\text { Disfagia; Crises } \\
\text { vertiginosas }\end{array}$ & $\begin{array}{l}\text {-Clínico: História Clínica; Exame } \\
\text { físico e neurológico } \\
\text {-Exame: Isolamento viral para } \\
\text { formas atípicas } \\
\text { Imunofluorescência direta ou } \\
\text { PCR em casos de dúvida }\end{array}$ & $\begin{array}{c}\text { Aciclovir } 500 \mathrm{mg} \text { IV por } 7 \\
\text { dias; Pregabalina } 1 \\
\text { comprimido de } 12 / 12 \mathrm{~h} \\
\text { por } 7 \text { dias; Perdnisona } \\
50 \mathrm{mg} \text { oral/dia por } 7 \\
\text { dias; Seguido de } \\
\text { valaciclovir e } \\
\text { pregabalina prescrito } \\
\text { após alta hospitalar }\end{array}$ \\
\hline
\end{tabular}

REAS/EJCH | Vol.Sup.n.55 | e3899 | DOI: https://doi.org/10.25248/reas.e3899.2020 Página 6 de 11 
Revista Eletrônica Acervo Saúde / Electronic Journal Collection Health ISSN 2178-2091

\begin{tabular}{|c|c|c|c|c|c|}
\hline Autores & Etiologia & Fatores de risco & Manifestação clínica & Diagnóstico & Tratamento \\
\hline $\begin{array}{l}\text { Jeon Y, et al. } \\
(2018)\end{array}$ & $\begin{array}{l}\text { Ativação de um } \\
\text { herpes vírus latente }\end{array}$ & Envelhecimento & $\begin{array}{l}\text { Secura ocular; Fraqueza } \\
\text { facial; Erupção } \\
\text { eritematosa; Vertigem; } \\
\text { Zumbido; Hipoacusia }\end{array}$ & $\begin{array}{l}\text {-Clínico: História clínica; Exame } \\
\text { físico } \\
\text {-Exame: PCR }\end{array}$ & $\begin{array}{l}\text { Aciclovir; Famcyclovir; } \\
\text { Prednisona }\end{array}$ \\
\hline $\begin{array}{l}\text { Ji Y, et al. } \\
(2019)\end{array}$ & $\begin{array}{l}\text { Vírus varicela } \\
\text { zoster }\end{array}$ & Não relatado & $\begin{array}{c}\text { Dor auricular; Erupções } \\
\text { vesiculares; Paralisia do } \\
\text { nervo facial; } \\
\text { Perda auditive; Tontura }\end{array}$ & $\begin{array}{l}\text {-Clínico: Anamnese; Exame físico } \\
\text { e neurológico } \\
\text {-Exame: RNM; Laboratorial; } \\
\text { Punção lombar - IgM VZV; PCR }\end{array}$ & $\begin{array}{l}\text { Aciclovir IV } 10 \mathrm{mg} / \mathrm{kg} \text { por } \\
21 \text { dias; Imunoglobulina } \\
\text { IV } 0,4 \mathrm{mg} / \mathrm{kg} \text { por } 5 \text { dias } \\
\text { Metilprednisolona } 40 \mathrm{mg} \\
\text { por } 10 \text { dias prescrito pós } \\
\text { alta hospitalar }\end{array}$ \\
\hline $\begin{array}{l}\text { Berardino FD, } \\
\text { et al. (2018) }\end{array}$ & $\begin{array}{l}\text { Reativação do vírus } \\
\text { varicela zoster }\end{array}$ & $\begin{array}{l}\text { Estresse físico e emocional; } \\
\text { Infecções bacterianas ou } \\
\text { virais; Trauma mecânico ou } \\
\text { cirúrgico; Imunodeficiência }\end{array}$ & $\begin{array}{l}\text { Paralisia facial; Erupções } \\
\text { herpéticas }\end{array}$ & $\begin{array}{l}\text {-Clínico: História clínica } \\
\text {-Exame: PCR }\end{array}$ & Aciclovir; Prednisona \\
\hline $\begin{array}{l}\text { Arya D, et al. } \\
(2018)\end{array}$ & $\begin{array}{l}\text { Reativação do vírus } \\
\text { varicela zoster }\end{array}$ & $\begin{array}{l}\text { Envelhecimento; Estresse } \\
\text { emocional; Tabagismo; } \\
\text { Diabetes; Depressão; } \\
\text { Imunodeficiência; Câncer; } \\
\text { Transplante de órgãos; } \\
\text { Corticosteroides; } \\
\text { Imunossupressores }\end{array}$ & $\begin{array}{c}\text { Otalgia; Vesículas } \\
\text { auriculares; Paralisia facial; } \\
\text { Disfagia; Tontura; Cefaleia; } \\
\text { Zumbido; Vertigem; } \\
\text { Rouquidão; Secura ocular; } \\
\text { Polineurite }\end{array}$ & $\begin{array}{l}\text {-Clínico: História clínica; Exame } \\
\text { físico e neurológico; House- } \\
\text { Brackman }\end{array}$ & $\begin{array}{l}\text { Valaciclovir } 1000 \mathrm{mg} 3 \mathrm{x} \\
\text { ao dia por } 5 \text { dias; } \\
\text { Prednisona } 90 \mathrm{mg} 1 \mathrm{x} \text { ao } \\
\text { dia por } 5 \text { dias }\end{array}$ \\
\hline $\begin{array}{l}\text { Zheng RW, et } \\
\text { al. (2017) }\end{array}$ & $\begin{array}{l}\text { Vírus varicela } \\
\text { zoster }\end{array}$ & Não relatado & $\begin{array}{c}\text { Polineurite; Otalgia; } \\
\text { Erupção vesicular; } \\
\text { eritematosa; Paralisia } \\
\text { facial; Deficiência auditive; } \\
\text { Tontura; Zumbido }\end{array}$ & $\begin{array}{l}\text {-Clínico: História clínica; Exame } \\
\text { físico } \\
\text {-Exame: Tomografia; RNM; PCR }\end{array}$ & $\begin{array}{c}\text { Cefotaxima sódica } \\
\text { Aciclovir IV +creme } \\
\text { tópico acetato de } \\
\text { Prednisona } 30 \mathrm{mg} \text { por } 3 \\
\text { dias; Seguido de } 20 \mathrm{mg} \\
\text { por } 3 \text { dias e } 10 \mathrm{mg} \text { por } \\
\text { mais } 3 \text { dias; } \\
\text { Acupuntura; Sangria; } \\
\text { Fitoterápicos }\end{array}$ \\
\hline $\begin{array}{l}\text { Tecellioglu M, } \\
\text { et al. (2017) }\end{array}$ & $\begin{array}{l}\text { Reativação do vírus } \\
\text { varicela zoster }\end{array}$ & $\begin{array}{c}\text { Tabagismo; Diabetes; } \\
\text { Cirurgias; Vasculites; Câncer; } \\
\text { Trauma }\end{array}$ & $\begin{array}{c}\text { Erupção cutânea; } \\
\text { Polineurite; Disfagia; Perda } \\
\text { auditive; Assimetria facial; } \\
\text { Rouquidão }\end{array}$ & $\begin{array}{l}\text {-Clínico: Anamnese; Exame físico } \\
\text { e neurológico } \\
\text {-Exame: Tomografia; RNM; } \\
\text { Audiometria tonal; Fibroscopia } \\
\text { laríngea; PCR }\end{array}$ & $\begin{array}{l}\text { Aciclovir IV } 750 \mathrm{mg} 3 \mathrm{x} \\
\text { ao dia por } 6 \text { dias; } \\
\text { Aciclovir } 750 \mathrm{mg} 2 \mathrm{x} \text { ao } \\
\text { dia por } 21 \text { dias }\end{array}$ \\
\hline
\end{tabular}

REAS/EJCH | Vol.Sup.n.55 | e3899 | DOI: https://doi.org/10.25248/reas.e3899.2020 Página 7 de 11 
Revista Eletrônica Acervo Saúde / Electronic Journal Collection Health ISSN 2178-2091

\begin{tabular}{|c|c|c|c|c|c|}
\hline Autores & Etiologia & Fatores de risco & Manifestação clínica & Diagnóstico & Tratamento \\
\hline $\begin{array}{l}\text { Montague SJ, } \\
\text { et al. (2017) }\end{array}$ & Não relatado & Envelhecimento & $\begin{array}{l}\text { Paralisia facial; Vesículas } \\
\text { herpéticas; Vertigem }\end{array}$ & -Clínico: Anamnese; Exame físico & $\begin{array}{l}\text { Aciclovir } 800 \mathrm{mg}, 5 x \text { ao } \\
\text { dia por } 7 \text { a } 10 \text { dias ou } \\
\text { Valaciclovir } 1000 \mathrm{mg}, 3 x \\
\text { ao dia por } 7 \text { a } 10 \text { dias } \\
\text { ou Famcyclovir } 500 \mathrm{mg} \text {, } \\
3 x \text { ao dia por } 7 \text { a } 10 \text { dias } \\
\text { Prednisona } 60 \mathrm{mg} \text { por } \\
\text { dia por } 14 \text { dias }\end{array}$ \\
\hline $\begin{array}{l}\text { Kondo N, et } \\
\text { al. (2018) }\end{array}$ & $\begin{array}{l}\text { Vírus Varicela } \\
\text { zoster }\end{array}$ & $\begin{array}{l}\text { Envelhecimento; Diabetes; } \\
\text { Imunodeficiência }\end{array}$ & $\begin{array}{l}\text { Deformidade facial; } \\
\text { Distúrbio funcional }\end{array}$ & $\begin{array}{l}\text {-Clínico: História Clínica; Exame } \\
\text { físico } \\
\text {-Exame: Audiometria tonal; } \\
\text { Impedanciometria; RNM }\end{array}$ & $\begin{array}{l}\text { Antivirais; Esteroides; } \\
\text { Cirúrgico }\end{array}$ \\
\hline $\begin{array}{l}\text { Miniti A, et al. } \\
(2000)\end{array}$ & $\begin{array}{l}\text { Vírus varicela } \\
\text { zoster }\end{array}$ & Não relatado & $\begin{array}{l}\text { Paralisia facial; Otalgia; } \\
\text { Vesículas herpéticas; } \\
\text { Hipoacusia; Vertigem }\end{array}$ & $\begin{array}{l}\text {-Clínico: Anamnese; Exame físico } \\
\text {-Exame: Tomografia; RNM }\end{array}$ & $\begin{array}{l}\text { Aciclovir ou Famcyclovir } \\
\text { Dexametasona } \\
0,1 \mathrm{mg} / \mathrm{kg} \text { sendo } 8 \mathrm{mg} \text { ao } \\
\text { dia }\end{array}$ \\
\hline $\begin{array}{l}\text { Garro A, et al. } \\
(2018)\end{array}$ & $\begin{array}{l}\text { Reativação do vírus } \\
\text { varicela zoster }\end{array}$ & Traumas; Otite média & $\begin{array}{l}\text { Paralisia facial; Perda } \\
\text { auditive; Zumbido; } \\
\text { Vesículas herpéticas }\end{array}$ & $\begin{array}{l}\text {-Clínico: História clínica; Exame } \\
\text { físico } \\
\text {-Exame: Diagnostico diferencial }\end{array}$ & $\begin{array}{l}\text { Metilprednisolona por } 10 \\
\text { dias; Prednisona por } 10 \\
\text { dias (crianças); } \\
\text { Valaciclovir; } \\
\text { Famcyclovir; Aciclovir }\end{array}$ \\
\hline $\begin{array}{l}\text { Paiva ALC, et } \\
\text { al. (2017) }\end{array}$ & $\begin{array}{l}\text { Reativação do vírus } \\
\text { varicela zoster }\end{array}$ & Imunodeficiência; Diabetes & $\begin{array}{l}\text { Otalgia; Perda auditive; } \\
\text { Paralisia facial; Vesículas }\end{array}$ & $\begin{array}{l}\text {-Clínico: História Clínica; Exame } \\
\text { Físico } \\
\text {-Exame: PCR - dúvida }\end{array}$ & $\begin{array}{l}\text { Prednisona } 1 \mathrm{mg} / \mathrm{kg} \text { por } \\
\text { 5-7 dias; Aciclovir IV ou } \\
\text { oral; Fisioterapia } \\
\text { motora; Massagem } \\
\text { terapêutica }\end{array}$ \\
\hline $\begin{array}{l}\text { Labin } E \text {, et al. } \\
(2017)\end{array}$ & Não relatado & Não relatado & $\begin{array}{l}\text { Otalgia; Vertigem; Paralisia } \\
\text { facial; Vesículas herpéticas }\end{array}$ & $\begin{array}{l}\text {-Clínico: Anamnese; Exame físico } \\
\text {-Exame: RNM }\end{array}$ & Esteroides; Aciclovir \\
\hline $\begin{array}{l}\text { Norris JH, et } \\
\text { al. (2019) }\end{array}$ & Não relatado & Não relatado & $\begin{array}{c}\text { Paralisia Facial; } \\
\text { Deformidade facial; Secura } \\
\text { ocular; Disfagia }\end{array}$ & Clínico: Anamnese; Exame físico & Não relatado \\
\hline
\end{tabular}

Legenda: RM: Ressonância Magnética; PCR: Reação em cadeia da polimerase.

Fonte: Almeida UTFH, et al., 2020.

REAS/EJCH | Vol.Sup.n.55 | e3899 | DOI: https://doi.org/10.25248/reas.e3899.2020 Página 8 de 11 


\section{DISCUSSÃO}

A síndrome de Ramsay Hunt é uma doença infecciosa causada pelo vírus varicela zoster, membro da família Herpesviridae. Foi descrita em 1907 por James Ramsay Hunt e ocorre por meio da reativação do vírus latente no gânglio sensorial da coluna vertebral e nervos cranianos. Diversas formas de reativação do vírus já foram esplanadas na literatura entre elas cirurgia, tumores, baixa da imunidade, entre outras. A polineuropatia correlacionada a síndrome é relatada em diversos estudos (PILTCHER OB, et al., 2015; SONG $\mathrm{H}$, et al., 2018; RAJATI M e ZARRINGHALAM MA, 2019; JEON Y e LEE H, 2018; BERARDINO FD e ZANETTI D, 2018; ARYA D, et al., 2018; ZHENG RW, et al., 2017; TECELLIOGLU M, et al., 2017).

A síndrome de Ramsay Hunt pode se apresentar como uma polineuropatia craniana, em virtude da proximidade anatômica dos nervos, assim como sua origem embriológica, disseminação hematogênica e disseminação transaxonal. Como observado entre o nervo corda do tímpano, lingual e maxilar, e entre o $\mathrm{n}$. facial e o vestibulococlear, que favorecem a progressão da doença. Em geral estão envolvidos o VIII, mais frequentemente, e os V, IX, X, XI, XII em menor proporção (PILTCHER OB, et al., 2015; SONG H, et al., 2018; RAJATI M e ZARRINGHALAM MA, 2019; ORTEGA MMM, et al., 2017; JEON Y e LEE H, 2018; JI Y, et al., 2019; ARYA D, et al., 2018).

O herpes zoster tem uma incidência anual de 3,2 a 4,2 casos por 1000. A incidência aumenta na quinta década de vida e atinge o pico na oitava década. Já a síndrome Ramsay Hunt tem incidência de 4,5\% a 9\%, é a causa mais comum de paralisia facial após a paralisia de Bell. A síndrome é rara em crianças menores de 6 anos, não têm predileção por sexo, o aumento da idade está associado ao aumento na incidência (PILTCHER OB, et al., 2015; SONG H, et al., 2018; RAJATI M e ZARRINGHALAM MA, 2019; JEON Y e LEE H, 2018; MONTAGUE SJ e MORTON AR, 2017).

São referidos como fatores de risco na literatura o envelhecimento, estresse emocional, tabagismo, diabetes, depressão, imunodeficiência, câncer, transplante de órgãos, cirurgias, traumatismo cranioencefálico e o uso de alguns medicamentos, incluindo corticosteroides e agentes imunossupressores. O principal fator de risco é o avançar da idade, em virtude da redução da imunidade. Os pacientes imunodeficientes são o segundo grupo mais suscetível ao desenvolvimento da doença (VALE SO, et al., 2019; RAJATI M e ZARRINGHALAM MA, 2019; ORTEGA MMM, et al., 2017; ARYA D, et al., 2018).

Qualquer fator de risco que acarrete depressão, mesmo que temporária, do sistema imunológico pode reativar o vírus latente no organismo e propiciar a manifestação da doença de forma ativa. Uma vez que o vírus da varicela é a primo-infecção e o zoster é a reativação do vírus, a severidade dessa enfermidade é diretamente dependente da imunidade celular do indivíduo (ORTEGA MMM, et al., 2017; BERARDINO FD e ZANETTI D, 2018; ARYA D, et al., 2018; TECELLIOGLU M, et al., 2017; KONDO N, et al., 2018).

Sua apresentação clássica é dada pela tríade otalgia, vesículas herpéticas e paralisia facial. Entretanto, outros sintomas foram descritos como perda auditiva, xeroftalmia, dormência facial, alteração do paladar, zumbido, tontura, nistagmo, entre outros. A manifestação clínica é variável e dependerá da extensão do acometimento neural e condição física do paciente em cada caso, e pode aparecer antes ou depois dos principais sintomas da síndrome de Ramsay Hunt (SONG H, et al., 2018; JEON Y e LEE H, 2018; JI Y, et al., 2019; ARYA D, et al., 2018; ZHENG RW, et al., 2017).

O vírus adentra o espaço intracraniano a partir da orelha interna, invadindo o nervo facial e o vestibulococlear e ascendendo ao núcleo do nervo facial, vestibular e núcleo posterior e anterior do nervo coclear. Tal acometimento resulta nas manifestações observadas como paralisia facial periférica, otalgia, tontura, zumbido e perda auditiva. No comprometimento do nervo trigêmeo observa-se perda da sensibilidade na face e alteração na deglutição (PILTCHER OB, et al., 2015; SONG H, et al., 2018; JI Y, et al., 2019; ARYA D, et al., 2018; ZHENG RW, et al., 2017).

A polineurite apresenta-se em 1,8\% dos pacientes com a síndrome de Ramsay Hunt. O envolvimento dos nervos cranianos aumenta com a idade. A neuralgia tem relação com o sistema nervoso simpático, assim, a dor pode induzir lacrimejamento, congestão nasal e salivação. A inclusão de diversos nervos resulta em um curso mais debilitante da doença (RAJATI M e ZARRINGHALAM MA, 2019; JEON Y e LEE H, 2018; ARYA D, et al., 2018; ZHENG RW, et al., 2017). 
Outra forma de apresentação clínica é sem vesículas herpéticas como observado no estudo de Zheng RW, et al. (2017) sobre a polineurite cranial causada pelo vírus da varicela zoster sem erupções. Assim como estudos realizados por Song $\mathrm{H}$, et al. (2018) já apontavam a existência da forma atípica da doença - "zoster sine herpete" (BERARDINO FD e ZANETTI D, 2018; TECELLIOGLU M, et al., 2017).

Em geral, o diagnóstico da síndrome é clínico, de acordo com a história e exame físico do paciente. A Avaliação inicial visa identificar a etiologia, local da lesão e o grau da paralisia facial. Para isso faz-se necessário uma anamnese minuciosa com questionamentos a respeito do início do quadro, tempo de evolução, sintomas concomitantes, episódios anteriores, doenças sistêmicas e familiares. E exame físico geral e otorrinolaringológico amplo com oroscopia, rinoscopia, otoscopia, acumetria, inspeção/palpação do pescoço e avaliação dos pares cranianos (PILTCHER OB, et al., 2015; ORTEGA MMM, et al., 2017; MINITI A, et al., 2000).

A paralisia facial precisa ser diferenciada entre central e periférica, portanto, a avaliação da mímica facial e sua mobilidade é de grande valor. A percepção do acometimento de toda a hemiface sugere lesão periférica. Para determinar o grau de paralisia é recomendado o uso da escala House-Brackmann, que apresenta graduação de I a VI, em que o grau I corresponde a normalidade e o grau VI a paralisia completa (PILTCHER OB, et al., 2015; VALE SO, et al., 2019; MINITI A, et al., 2000; GARRO A e NIGROVIC LE, 2018).

Quanto à topografia da lesão, são preconizados três exames: Teste de Schirmer, pesquisa do reflexo estapediano e avaliação da gustação. O teste de Schirmer avalia a função das glândulas lacrimais por meio da colocação de tiras de papel filtro no terço médio da pálpebra inferior bilateral, considera-se patológico redução de $27 \%$ a $30 \%$ do lacrimejamento entre os olhos. Tal achado aponta lesão no nervo petroso superficial maior na emergência do gânglio geniculado (PILTCHER OB, et al., 2015; MINITI A, et al., 2000).

A pesquisa do reflexo estapediano se dá por meio da imitanciometria. A presença deste reflexo sinaliza lesão distal ao ponto de surgimento do nervo do músculo estapédio, entretanto, o inverso não é verdadeiro, uma vez que outras condições podem justificar sua ausência.

Quanto ao teste da gustação, é realizado com as quatro sensações básicas: salgado, doce, azedo e amargo, nos 2/3 anteriores da língua. A falta da percepção sugere acometimento do nervo corda do tímpano e lesão do nervo facial proximal à sua emergência (PILTCHER OB, et al., 2015; MINITI A, et al., 2000).

Outros exames complementares podem ser sugeridos em casos específicos como a eletroneurografia e eletromiografia utilizados nos casos de paralisia facial completa. Ressonância magnética quando há suspeita de trauma, encefalite, polineurite e tumor, o exame de Tomografia computadorizada pode ser usado para descartar acidente vascular encefálico. Já o exame Laboratorial como isolamento de culturas e reação em cadeia de polimerase - PCR, para casos atípicos ou escolha do tratamento/profilaxia (PILTCHER OB, et al., 2015; ORTEGA MMM, et al., 2017; JI Y, et al., 2019; TECELLIOGLU M, et al., 2017; MINITI A, et al., 2000).

O diagnóstico passa a ser desafiador quando as manifestações clínicas diferem da apresentação clássica da doença, necessitando assim, atenção especial para o diagnóstico diferencial precoce de Ramsay Hunt. Lesões ou úlceras na orofaringe, dor miofascial e polineurite cranial devem ter a infecção pelo vírus varicela zoster como diagnóstico diferencial.

A síndrome é considerada uma patologia rara, e seus sintomas diversos podem mascarar a doença e atrasar seu diagnóstico e tratamento (JI Y, et al., 2019; BERARDINO FD e ZANETTI D, 2018; ZHENG RW, et al., 2017; TECELLIOGLU M, et al., 2017).

É preconizado o tratamento medicamentoso com corticosteroides e antivirais e seu início deve ser instituído dentro das primeiras 72 horas. A Prednisona é o corticoide de escolha por sua ação anti-inflamatória e deve ser utilizada por 10 a 14 dias. Os antivirais de escolha são Valaciclovir, Famcyclovir ou Aciclovir por 7 a 10 ou 14 dias, sendo os dois primeiros as drogas de escolha, devido uso de menor dose posológica, permitindo melhor adesão ao tratamento (PILTCHER OB, et al., 2015; ORTEGA MMM, et al., 2017; JEON Y e LEE H, 2018; MONTAGUE SJ e MORTON AR, 2017; MINITI A, et al., 2000; GARRO A e NIGROVIC LE, 2018; PAIVA ALC, et al., 2017; LABIN E, et al., 2017). 
O uso do corticoide aumenta a probabilidade de recuperação, encurta tempo de doença e reduz a sincinesia da paralisia facial. Já os antivirais são conhecidos por seu efeito virostático, impedindo a replicação do vírus por meio da cadeia de polimerase do Ácido Desoxirribonucleico (DNA). Logo, o tratamento com tais drogas se faz de grande importância, visto que sem a terapia apropriada, apenas $20 \%$ dos pacientes alcançam recuperação completa (PILTCHER OB, et al., 2015; SONG H, et al., 2018; ORTEGA MMM, et al., 2017; GARRO A e NIGROVIC LE, 2018).

A descompressão cirúrgica não é indicada nos casos de Ramsay Hunt, pois trata-se de envolvimento do tecido nervoso e não compressão em si. Ademais, estudo realizado por Kondo N, et al. (2018) conclui que tal cirurgia tem mau prognostico em pacientes $\geq 60$ anos e não há evidências estabelecidas que apoiem o uso do tratamento cirúrgico13,14. Quanto à terapia não medicamentosa, é indicada a fisioterapia motora após fase aguda e remissão da dor, acupuntura e massagem terapêutica (ZHENG RW, et al., 2017; PAIVA ALC, et al., 2017).

O tratamento precoce é essencial para diminuir o tempo de doença ativa, reduzir o dano neural e possível neuralgia pós herpética, visto que a síndrome tem altas taxas de lesão permanente e baixas taxas de cura espontânea; além da repercussão estética e funcional, que podem afetar a qualidade de vida do paciente acometido (JI Y, et al., 2019; BERARDINO FD e ZANETTI D, 2018; ARYA D, et al., 2018; ZHENG RW, et al., 2017; NORRIS JH, et al., 2019).

\section{CONSIDERAÇÕES FINAIS}

Na presente revisão foi possível constatar a heterogeneidade nos estudos sobre a Síndrome de Ramsay Hunt nos seus aspectos etiológicos, fatores de risco, quadro clínico, diagnóstico e tratamento. Entretanto, todos apontam para a importância de seu reconhecimento, característica clínica e seguimento; uma vez que o rápido diagnóstico e tratamento diminuem o tempo de doença ativa, reduz o dano neural e possível neuralgia pós-herpética, diminuindo risco de sequelas permanentes da doença.

\section{REFERÊNCIAS}

1. ARYA D, et al. Ramsay Hunt Syndrome with Multiple Cranial Neuropathy in an Human Immunodeficiency Virus (HIV) Patient. Am J Case Rep, 2018; 19:68-71.

2. BERARDINO FD, ZANETTI D. Typical or Atypical Ramsay-Hunt Syndrome in Delayed Facial Palsy After Stapedectomy? J Int Adv Otol, 2018; 14(2):233-8.

3. CARRICO C. Relato de um caso de Síndrome de Ramsay Hunt. Rev Port Clin Geral, 2011, 27(6): 554-556.

4. GALLEGO MPO, et al. Síndrome de Ramsay Hunt: a propósito de un caso. Rev Clin Med Fam, 2016, 9(2): 119-122.

5. GARRO A, NIGROVIC LE. Managing Peripheral Facial Palsy. Annals of Emergency Medicine, 2018; 71(5): 618-24.

6. JEON Y, LEE H. Ramsay Hunt syndrome. Dent Anesth Pain Med, 2018; 18(6):333-337.

7. JI Y, et al. Ramsay Hunt syndrome with pontine lesion - A case report. Medicine, 2019; 98(5).

8. KONDO N, et al. Patients Over 60 Years of Age Have Poor Prognosis in Facial Nerve Decompression Surgery with Preserved Ossicular Chain. Int Adv Otol, 2018; 14(1):77-84.

9. LABIN E, et al. Teaching Neurolmages: Classic Ramsay Hunt syndrome and associated MRI findings. Resident and fellow Section, 2017; 89(7).

10. MINITI A, BENTO RF, BUTUGAN O. Otorrinolaringologia clínica e cirúrgica. 2 ed. São Paulo: Atheneu, 2000; 368p.

11. MONTAGUE SJ, MORTON AR. Ramsay Hunt syndrome. CMAJ, 2017; 189(8).

12. NORRIS JH, et al. Exploring Patient Experience of Facial Nerve Palsy to Inform the Development of a PROM. Plastic and Reconstructive Surgery - Global Open, 2019; 7.

13. ORTEGA MMM, et al. Síndrome de Ramsay Hunt tipo II en mujer mayor de 90 años. Rev Fac Cienc Méd, 2017; 14(2):46-51.

14. PAIVA ALC, et al. Facial paralysis due to Ramsay Hunt syndrome - A rare condition. Rev Assoc Med Bras, 2017; 63(4):301-302.

15. PILTCHER OB, COSTA SS, MAAHS GS, KUHL G. Rotinas em otorrinolaringologia. 1 ed. Porto Alegre: Artmed, 2015; $148 \mathrm{p}$.

16. RAJATI M, ZARRINGHALAM MA. Ramsay Hunt Syndrome Associated with True Vocal Cord Palsy- A Case Report. Iranian Journal of Otorhinolaryngology, 2019; 31(2):115-118.

17. SONG H, et al. Clinical Characteristics of Dizziness Associated with Acute Peripheral Facial Palsy. J Audiol Otol, 2018; 22(3):148-153.

18. TECELLIOGLU M, et al. A Rare Presentation of Cranial Polyneuropathy Without Rash Caused by Varicella Zoster Virus. Med Arch, 2017; 71(4):293-95.

19. VALE SO, et al. Medicina física e de reabilitação no tratamento da paralisia de Bell: qual a evidência? Rev Port Med Geral e Fam, 2019; 35(2):116-25.

20. ZHENG RW, et al. A case study of Ramsay Hunt Syndrome in conjunction with cranial polyneuritis. Medicine, 2017; 96(47).

REAS/EJCH | Vol.Sup.n.55 | e3899 | DOI: https://doi.org/10.25248/reas.e3899.2020 Página 11 de 11 